\title{
Masculinidades Alternativas: Varones que se Narran al margen del Modelo Hegemónico y Generan Cambios a través de la Educación
}

\author{
Alternative Masculinities. Men Giving a Narrative Account \\ beyond the Hegemonic Model and Generate Change through \\ Education
}

Pedro Uribe Roncallo *

Fundación Ilusión Viril, Chile

\begin{abstract}
Entendiendo que la educación es uno de los principales agentes socializadores de género y dada la importancia de la prevención de la violencia de género en la sociedad, explorar y comprender las historias de vida de varones que han construido una masculinidad alternativa puede dar luces para promover desde la educación modelos de masculinidades diferentes al tradicional y la posibilidad de contar con referentes masculinos que contribuyan a la construcción de identidades masculinas no hegemónicas. Por ello, los objetivos de nuestra investigación apuntan a la comprensión de aquellos hitos, experiencias de vida y motivaciones que hace que un varón construya una masculinidad alternativa al modelo tradicional de masculinidad. Se recolecta esta información a través de entrevistas en profundidad a 19 participantes que se identifican con el género masculino, mayores de edad provenientes de diversos orígenes, identidades y orientaciones sexuales que residen actualmente en la ciudad de Barcelona. Se empleó un enfoque narrativo-biográfico ya que la información extraída fue analizada e interpretada a partir de relatos y reflexiones personales, pudiendo así aproximarnos a la perspectiva de estos varones sobre aquellos sucesos que han tenido un impacto en sus identidades e historias de vida y así comprender si son capaces de educar a otros varones, promover estos valores e implicarse en acciones de igualdad y no violencia.
\end{abstract}

Descriptores: Virilidad; Identidad masculina; Masculinidad hegemónica; Violencia de género; Educación moral.

Understanding that education is one of the main gender socializing agents and, thus, a space in which prevention strategies against gender violence of society are required, we consider it relevant to explore and understand the life stories of men who have built alternative masculinities. Studying these non-traditional life stories can help to develop educational strategies that promote masculinity models other than the traditional ones. Consequently, such education strategies can create nontraditional masculinity referents that contribute to the construction of nonhegemonic masculine identities. Therefore, the aim of our research was to comprehend those milestones, life experiences and motivations that lead a man to the construction of an alternative masculinity. The data was collected through indepth interviews with 19 participants who identify themselves as male, reached the age of legal majority (18 years), have different origins, identities, and sexual orientations. All the participants were living in Barcelona at the time of the interviews. Since the data was biographical, a narrative-biographical methodological approach was used to analyze and interpret the stories and personal reflections of the participants. This enabled us to comprehend the participants' perspectives and events that had an impact on their identities and life stories. Furthermore, the analyses helped us to understand if the participants were able to educate other men, would promote non-traditional values regarding masculinity, and would get involved in actions that promote gender equality and non-violence.

Keywords: Virility; Male identity; Hegemonic masculinity; Gender violence; Moral education.

*Contacto: pedromigueluribe@gmail.com

ISSN: 0718-7378

www.rinace.net/rlei/
Recibido: 25/06/2020

$1^{\text {a }}$ Evaluación: 10/07/2020

Aceptado: $\quad 19 / 08 / 2020$ 


\section{Introducción}

El valor que se la ha otorgado a lo masculino y al hecho de ser hombre, se ha traducido en una supremacía en detrimento de lo femenino, generando consecuencias en la vida tanto de hombres como de mujeres. Este modelo referencial ha tenido una repercusión a toda escala en nuestra sociedad, atravesando la esfera de lo público y lo privado y teniendo un efecto tanto a nivel colectivo como individual. Esta macroestructura denominada patriarcado, ha instalado ideas, valores y sentidos en diferentes ámbitos de lo social, reproduciéndose a nivel político, sanitario, económico y evidentemente, también en el espacio educativo y el mundo académico. La manera en que se encuentra estructurada la educación tradicional conlleva en sí complejos mecanismos que tienden a promover una serie desigualdades, estereotipos y violencias, teniendo un efecto directo en el desarrollo identitario y socioafectivo de niños y niñas. Henry Giroux (1979) plantea que habría un currículum oculto para fundamentar la manera en que los centros educativos entregan normas, valores y creencias no afirmadas explícitamente, las cuales se transmiten a la/os estudiantes a través de estructuras subyacentes tanto en el contenido formal como en las relaciones de la vida escolar y en el aula, es decir, se transmiten de forma solapada y moldean su experiencia subjetiva. Aunque diversos estudios refieren que ya no hay una brecha de género en el acceso a estudios secundarios y terciarios, sí se observan importantes diferencias en el tipo de especialidades y oficios elegidos por hombres y mujeres en ambos niveles educativos, variables no académicas que explican las brechas de género en el aprendizaje y estereotipos y sesgos de género que siguen impactando las relaciones entre los géneros y la perpetuación de la dominación masculina en instituciones de educación (Covacevich y Quinquela-Dávila, 2014; Del Rio, 2019; Nadal, 2008; Olarte y de Keijzer, 2018). Ante un contexto social y político como el actual, el mundo académico y educativo ha sido interpelado para que ponga urgencia en la creación de políticas coeducativas, acciones que promuevan la igualdad de género como eje que influya en las relaciones intra genéricas y medidas para prevenir el acoso y la violencia.

A nivel internacional, según la OMS (2014) casi un tercio (30\%) de todas las mujeres que han tenido una relación ha sufrido violencia física o sexual por parte de su pareja. Además, se calcula que un $98 \%$ de las denuncias por violencia de género es perpetrada por varones, cifras que coinciden con países de Europa y Latinoamérica (ProMundo y ONU Mujeres, 2017). De este modo, las iniciativas que impliquen a varones en estas temáticas podrían permitir mitigar los efectos de la violencia de género. En relación a esto, existen autores que afirman que habría un nexo entre la masculinidad y el ejercicio de la violencia. Por ejemplo, Daniel Gabarró (2009) dice que habría una relación directa entre la masculinidad hegemónica o tradicional y diferentes problemas sociopolíticos y educativos. Este autor plantea que gran parte de los problemas sociales actuales estarían relacionados con los hombres y la forma en que construyen su masculinidad. En el ámbito de la educación, quienes perpetran el acoso escolar o bullying son mayoritariamente varones. Cerca de un $85 \%$ de quienes presentan problemas de conducta graves en aulas especiales de la ESO son chicos (Gabarró, 2009). Además, las víctimas recurrentes serían otros chicos que no siguen los mandamientos de la masculinidad tradicional y son percibidos por sus pares como "próximos a lo femenino". Así, el acoso escolar que tiende a ser homófobo soterradamente sería también sexista.

En relación a la violencia machista, el Ministerio de Sanidad del Estado español indica que han sido asesinadas 712 mujeres entre 2003 y 2013, la mayoría a manos de sus parejas o 
exparejas. Del total de denuncias, el $97 \%$ de las personas que agreden a sus parejas serían hombres. Por otra parte, en relación a la violencia y la criminalidad, en Catalunya el 93\% de la población reclusa es masculina (Idescat, 2013) cifra que se condice con el resto de las cárceles del mundo. Si hablamos de salud mental, según cifras de la OMS (2014) en el caso del Reino Unido, el suicidio es la principal causa de muertes en varones menores de 45 años. De hecho, a nivel mundial, se calcula que los varones tienen tres veces más posibilidades de morir por suicidio que las mujeres (en Estados Unidos un 3,5 y en Rusia y Argentina más de 4). Según estos datos, los principales factores de riesgo tienen que ver con los mandatos de la masculinidad y la comunicación: a los varones no se les permite expresar su sufrimiento y no son capaces de pedir ayuda.

Dada la situación contingencia del movimiento feminista y los avances globales de la agenda de género, cabe preguntarse cuál es el rol de los varones en el contexto actual y en particular, si los varones estamos haciendo algo para desaprender el sexismo en el que fuimos criados. Si existe consenso de que la socialización de género comienza en la infancia y, además, de que el machismo se educa, ¿Qué papel estamos jugando los varones en preservar o transformar las diferencias de género? ¿En qué medida nuestra identidad masculina ayuda a mantener estas desigualdades? ¿Qué tipo de valores y actitudes promovemos los varones con nuestra masculinidad? ¿Somos capaces de transmitir valores como la igualdad y la equidad a nuestros símiles? ¿Qué situaciones ha de vivir un varón para asumir una posición disidente y cuestionar sus prácticas sexistas? ¿Seremos los varones capaces de enseñar otros modelos de masculinidad que denuncien la violencia machista, la misoginia y la homofobia? ¿Qué efectos produciría este cambio en las biografías de los varones y en sus relaciones con las/os demás?

Desde ésta óptica, a través de esta investigación, hemos querido dar luz a los relatos de vida de varones que se han propuesto generar cambios en sus vidas gracias a la sensibilización de género y su proximidad con el feminismo, transformando sus relaciones y sus entornos, promoviendo valores divergentes a los mandatos de género tradicionales, poniendo en cuestión algunos de sus privilegios y reflexionando en torno a los efectos cotidianos de cómo opera el sistema patriarcal en cada uno de ellos.

\section{Conceptualización teórica}

\subsection{Género y educación}

Según diversos/as autores/as, existirían cuatro principales agentes socializadores de género en nuestra sociedad. Para Gayle Rubin (1975) serían estos los encargados de transmitir y reproducir el modelo hegemónico que rige el sistema sexo-género: familia, grupo de pares, medios de comunicación y la escuela. La socialización de género resulta efectiva principalmente porque ese modelo se vuelve altamente deseable y se retroalimenta constantemente, configurándose como norma un sólo tipo de cuerpo (hombre o mujer), identidad (cisgénero) y deseo (heterosexual), excluyendo y marginando todo aquello que se halla fuera de ésta (intersexuales, transgéneros y homo/bi/asexuales principalmente).

Al ser la escuela uno de los principales socializadores de género, las/os profesionales de la educación educamos a niños y niñas reforzando estos valores tradicionales, promoviendo estereotipos y roles asignados según el género. Entenderemos como roles de género "aquellos comportamientos definidos como masculino y femenino en diferentes épocas y en una cultura determinada. Estas conductas también se encuentran 
generalmente en concordancia con el sexo biológico y la identidad de género de las personas" (Bardi et al., 2005, p. 44). Sobre ello, Michael Kaufman (1994) señala que "la interiorización de las relaciones de género es un elemento en la construcción de nuestras personalidades, es decir, la elaboración individual del género, y nuestros propios comportamientos contribuyen a fortalecer y a adaptar las instituciones y estructuras sociales de tal manera que, consciente o inconscientemente ayudamos a preservar los sistemas patriarcales" (p. 7).

\subsection{Ciclo vital masculino: Identidades y sexualidades}

Respecto a los varones, Enrique Gil Calvo (2001) afirma que la identidad masculina se construye a través de la interacción con el linaje paterno y se reafirma con los pares. Para él, padre e hijo aparecen como identidades fijas y vinculadas por una masculinidad que se lleva en la sangre, como inmutables en el tiempo y con una forma de relación ya establecida. En esta forma de relación, la autoridad del padre revela la masculinidad subordinada a este. El hombre se hace hombre con los hombres, entre los hombres, en complicidad con otros hombres y en oposición con lo feminizado. González Moreno y Camacaro Gómez (2013) apoyan esta idea a través de lo planteado por Elisabeth Badinter (1992) señalando que "la identidad masculina se define por oposición a lo que es femenino. El hombre para hacer valer su identidad masculina debe convencer a los demás que no es una mujer, que no es un bebé y que no es un homosexual. La masculinidad necesita moldearse y demostrarse constantemente" (p. 1).

En la pubertad la transición de niño a hombre se hace real. "Son los/as adolescentes los/as más susceptibles a demostraciones de la virilidad y feminidad, ya que se encuentran en un periodo vital en el que se ven impelidos de afirmarse como adultos" (Espada, 2004, p.7). Sobre la virilidad, Pierre Bourdieu (1998) es concluyente al señalar que predominaría en los varones, un principio de conservación y del aumento del honor, siendo un atributo indisociable. Este proceso es fundamental para comprender por qué el cuerpo y la identidad masculina configuran tan fuertemente la construcción individual de la masculinidad. Al respecto Kaufman (1994) afirma que los hombres como individuos interiorizamos estas concepciones en el proceso de desarrollo de nuestras personalidades ya que, nacidos en ese contexto, aprendemos a experimentar nuestro poder como la capacidad de ejercer el control y dominar. "Los hombres aprenden a aceptar y a ejercer ese poder de esta manera porque les otorga privilegios y ventajas que ni los niños ni las mujeres disfrutan en general" (Kaufman, 1994, p. 6).

\subsection{Masculinidades}

En la actualidad, existen visiones heterogéneas acerca del concepto de masculinidad. Al respecto, Oscar Guasch (2006) refiere que "la masculinidad es una forma que adopta el género y el género es una estructura social, orden simbólico y práctica social. Es una variable universal de estratificación social que regula roles y el acceso y la distribución a los recursos, pero que cambia en el espacio/ tiempo y que puede ofrecer más de dos identidades" (p. 15). Por su parte, Raewyn Connell (1995) dice que "el concepto es inherentemente relacional. La masculinidad existe sólo en contraste con la feminidad (...) la masculinidad no es un objeto coherente acerca del cual se pueda producir una ciencia generalizadora” (p. 2).

Luis Bonino (2008) va un poco más allá y afirma que esto es así "porque los varones (y la masculinidad) se colocan (y son colocados) desde el inicio de Occidente como los propietarios de la "normalidad"/salud/cordura. Por tanto, ellos no constituyen problema, 
sus teorías y prácticas de sí son la unidad ideal y única de medida de lo humano y desde ellas se producen las normas que definen lo "normal". Y por esto sus quehaceres quedan incuestionados y silenciadas por "normales" (p. 2). Pierre Bourdieu (1998), analiza la relación existente entre el poder y la virilidad, señalando que la masculinidad "es eminentemente relacional, construido ante y para los restantes hombres y contra la feminidad, en una especie de miedo hacia lo femenino, y en primer lugar en sí mismo” (p. 71); "La virilidad, entendida como capacidad reproductora, sexual y social, pero también como aptitud para el combate y para el ejercicio de la violencia (en la venganza sobre todo) es fundamentalmente una carga" (p. 68). Sobre ello, Kaufman (1994) afirma que "lo que concebimos como masculinidad es el resultado de la forma como se combinan nuestro poder y nuestra alienación. Nuestra alienación aumenta la solitaria búsqueda del poder y enfatiza nuestra convicción de que el poder requiere la capacidad de ser distante" (p.10) y agrega "no existe una masculinidad única, ni una experiencia única de ser hombre. La experiencia de distintos hombres, su poder y privilegio real en el mundo se basa en una variedad de posiciones y relaciones sociales" (p. 11).

\subsection{Masculinidad hegemónica y sus consecuencias}

Entenderemos por masculinidad hegemónica (MH) según Connell (1995) como la masculinidad que ocupa la posición hegemónica o dominante en un modelo definido de relaciones de género (p. 11). Es decir, es un modelo explicativo que permite dar cuenta que las relaciones de poder existentes en los varones son producto de una dinámica cultural en la cual un grupo exige una supremacía y sostiene una posición de liderazgo y dominación sobre los demás. La hegemonía es problemática en cuanto la agenda de unos pocos que detentan un poder intentan imponer su agenda a toda la ciudadanía a través de la opresión y la dominación, tanto de los otros varones no hegemónicos como de las mujeres. Ante esto, Bonino (2008) dice que hay que dar "un paso más allá: no sólo adentrarnos en las problemáticas de la masculinidad, sino también poder pensar la masculinidad (tal como es definida actualmente) como problemática" (p. 13).

Según Kaufman (1994) la adquisición de la masculinidad hegemónica sería un proceso a través del cual los hombres llegan a suprimir toda una gama de emociones, necesidades y posibilidades, tales como el placer de cuidar de otros, la receptividad, la empatía y la compasión, experimentadas como inconsistentes con el poder masculino. Esto generaría una especie de analfabetismo emocional y a la vez una paradoja. "Existe en la vida de los hombres una extraña combinación de poder y privilegios, dolor y carencia de poder. Por el hecho de ser hombres, gozan de poder social y de muchos privilegios, pero la manera de cómo hemos armado ese mundo de poder causa dolor, aislamiento y alienación tanto a las mujeres como a los hombres" (Kaufman, 1994, p. 1). María Jesús Izquierdo (2007) dice que "ser hombre no sólo reporta beneficios, sino que cuesta" (p. 3).

Por su parte, Jokin Azpiazu (2017) plantea que quien es un hombre y encarna una masculinidad hegemónica deberá, de diferentes maneras en diferentes contextos, demostrar su posición como hombre y luchar para que no le sea arrebatada. Para Michael Kimmel (1994) la definición de la virilidad está en constante cambio y por ello, hay quienes luchan por reafirmarla sin tomar consciencia que también está cargada de aprendizajes culturales. Él afirma que los hombres pensamos que la virilidad es eterna, una esencia sin tiempo que reside en lo profundo del corazón de todo hombre. Pensamos que la virilidad es una cosa, una cualidad que alguien tiene o no tiene. Así la homofobia sería un principio organizador de nuestra definición cultural de virilidad. La homofobia, más que el miedo 
irracional por los hombres gay, es el miedo de lo que podemos percibir como gay. Por ello, todo lo asociado a lo femenino tiende a ser rechazado y vetado.

\subsection{Masculinidades alternativas}

A partir del siglo XIX, el papel de mujeres y hombres en la sociedad ha mutado. En la actualidad, han surgido autores/as que describen como un fenómeno reciente el surgimiento de varones igualitarios o movimientos de hombres que están promoviendo y buscando activamente la igualdad de género en diversos espacios. Esto claro, como consecuencia de una llamada crisis de la masculinidad y de los cuestionamientos que socialmente se han hecho al género masculino como producto del patriarcado y la constante desvalorización de la figura de la mujer. Se podría afirmar que gracias a esta crisis nos encontramos en una época de transición: de los mandatos de la MH a los valores igualitarios.

Miguel Llorente (2009) ve este cambio de una manera crítica y con menos optimismo. Refiere que muchos hombres han cambiado solamente en lo retórico y en lo estético, pero las actitudes e ideas machistas se mantienen intactas. "Cambiar para seguir igual": ese ha sido el compromiso de los hombres para adaptarse a los tiempos, a las modas y a las circunstancias sin renunciar a su posición de poder" (p. 15). Para Connell (1995) este cambio es evidente:

Las relaciones de poder muestran las evidencias más visibles de las tendencias de crisis:
un histórico colapso de la legitimidad del poder patriarcal, y un movimiento global
por la emancipación de las mujeres. Esto es alimentado por la contradicción
subyacente entre desigualdad de mujeres y hombres, por un lado, y por las lógicas
universalizantes de las estructuras del Estado moderno y de las relaciones de mercado,
por otro. (p. 19)

Para Rafael Montesinos (2002) esta crisis masculina obedece primero a un proceso complejo de cambio cultural a partir del cual se advierte "la emergencia de nuevas estructuras simbólicas en la que las mujeres comienzan a desarrollar habilidades tradicionalmente resguardadas a los hombres, poniéndose en peligro su capacidad proveedora y colocando en riesgo su autonomía. La situación podría resumirse en incapacidad masculina para resignificar las nuevas condiciones culturales y asumir un nuevo patrón genérico que lo libere de las imposiciones de la cultura machista" (citado en González Moreno y Camacaro Gómez, 2013, p.1).

Vamos a entender por masculinidades alternativas o igualitarias aquellos varones que han construido una identidad masculina desmarcándose del modelo de la masculinidad hegemónica. Se caracterizan por denunciar y rechazar la violencia machista, estar a favor de la igualdad de género (o compartir ideas con el feminismo) y promover (consciente o inconscientemente) valores igualitarios que se traduzcan en prácticas cotidianas que crean condiciones de igualdad y no violencia hacia las mujeres. Por supuesto, este concepto no puede ser considerado un atributo o adjetivo. Se propone como un marco referencial para comprender las configuraciones identitarias que los varones que se están reeducando y repensando su masculinidad están definiendo actualmente en términos transicionales. En general, todos estos hombres provienen de una formación y crianza bajo el modelo de la $\mathrm{MH}$, pero se encuentran actualmente repensando su masculinidad y pudiendo identificar aquellos aspectos patriarcales y sexistas que permanecen en sí mismos. Es decir, implica no un objetivo logrado ni un status nuevo, sino un proceso permanente e infinito de revisión de su subjetividad. 


\section{Propuesta metodológica}

Este estudio se enmarca en un enfoque interpretativo o de corte cualitativo, ya que pretende comprender un aspecto de la realidad social vinculada a la masculinidad que guarda relación con las vivencias de varones que han construido una masculinidad no hegemónica y/o alternativa a lo largo de su vida y por otra parte, se pretendió describir y sistematizar tales experiencias. Se trabajó con una aproximación biográfico-narrativa por ser un marco metodológico y explicativo que permitió acercarnos a los relatos de vida de los participantes y que además les permitiera reflexionar a partir de esas vivencias. En palabras de Antonio Bolívar (2002), el método narrativo "comporta un enfoque específico de investigación con su propia credibilidad y legitimidad para construir conocimiento en educación. Reclama, por tanto, un modo distintivo del paradigma cualitativo convencional, sin limitarse a una metodología de recolección y análisis de datos. En esa medida, altera algunos supuestos de los modos asentados de investigar, haciendo de esta práctica algo más accesible, natural o democrática. Contar las propias vivencias y "leer" (en el sentido de "interpretar") dichos hechos y acciones, a la luz de las historias que los actores narran, se convierte en una perspectiva peculiar de investigación” (p. 3).

Elaboramos una estrategia de muestreo intencionado, es decir, realizamos una selección de casos en función de la relevancia que estos tenían para nuestro estudio y, por tanto, sean quienes nos aporten información más significativa. De esta manera, nuestro contexto ha quedado conformado por 19 participantes que se identifican como varones. Se eligió una muestra que es coherente con el método inductivo, en el sentido que no es de nuestro interés producir datos que sean generalizables sino transferibles. Los participantes presentan tres elementos en común: se identifican con el género masculino, son mayores de edad y residen actualmente en la ciudad de Barcelona. Sobre el contexto, hemos elegido la ciudad de Barcelona por un asunto de viabilidad y acceso por una parte y por otro lado, porque Catalunya como región y, en particular, su capital Barcelona, es un epicentro donde la temática del género se aborda e implementa a nivel institucional a través del Ayuntamiento y políticas locales, a nivel ciudadano y territorial por medio de juntas y por supuesto, a nivel académico y educativo, generándose importante cantidad de producción académica, literaria e investigativa en esta materia. Además, existe una red a nivel nacional de hombres igualitarios, con sede en diferentes ciudades de España y, en Cataluña se encuentra AHIGE Catalunya que reúne esfuerzos y trabajos de diferentes grupos de hombres de la región, por ende, se perfila como un lugar donde ya existe una red y colectividades de diferente índole que convoca a varones que se han familiarizado con el feminismo y la igualdad.

La principal técnica de recolección de información que empleamos para nuestro estudio es la entrevista en profundidad que realizamos a los 19 participantes de nuestro contexto. Junto con ella, realizamos un cuestionario inicial para identificar y caracterizar a los varones que entrevistamos. Principalmente, nos interesaba poder obtener información relevante de carácter personal e identitario para que pudiera servir posteriormente al momento del análisis de los resultados.

Para el análisis de los datos obtenidos, nos centramos en los resultados más relevantes y significativos de los relatos de vida de los participantes. Por ello, pensamos que la técnica más adecuada es el análisis de contenido. Esta herramienta nos permitió organizar las entrevistas una vez que fueron transcritas, en formas de categorías y subcategorías, configurando así un árbol de información que pudo ser agrupado y dividido a fin de 
destacar y dar respuesta a las preguntas directrices que orientan nuestra investigación y así facilitan la interpretación de estos datos.

\title{
4. Resultados
}

En este apartado intentaremos dar luces de los resultados obtenidos gracias al análisis de contenido que realizamos. Debido a la gran cantidad de información que obtuvimos, hemos preferido centrarnos en los ejes significativos y en aquellos elementos que debido a la saturación de conceptos de forma orgánica se fueron transformando en las bases de nuestro análisis.

\subsection{Familia}

\subsubsection{Paternidad igualitaria y referentes masculinos}

Observamos que los orígenes de estos hombres son diversos y que provienen de sistemas familiares complejos y variopintos. Aun así, nos pareció interesante destacar que estos hombres provienen de modelos de crianza y sistemas familiares principalmente con tres características: Autoritarismo parental, que se caracteriza por ser un tipo de familia jerárquica donde la figura del padre es el dueño de la autoridad y estos hombres, al rebelarse contra esta figura, han construido su identidad: "Mi padre tiene una masculinidad muy hegemónica. Tenemos una relación muy compleja. Por un lado, siendo pequeñito, recuerdo afecto por su parte, pero cuando voy teniendo mi propia identidad, ya sí que empiezo a recibir maltratos por su parte entonces" (E16, trabajador social, 34 años). Por otra parte, vemos familias donde la figura paterna surge como un referente masculino igualitario. En estos sistemas familiares la figura del padre se destaca por transformarse en un modelo a seguir y un referente de género positivo para estos hombres. En general, estaríamos hablando de varones que ejercen la paternidad desde un lugar diferente al hegemónico: se han implicado en lo doméstico, practican la corresponsabilidad, expresan abiertamente sus afectos a sus hijo/as y establecen comunicaciones con ellas/os que va más allá del rendimiento y los logros deportivos:

\begin{abstract}
Mi padre, sin ninguna duda, ha sido un referente de género. Mi padre no es el típico padre. Es una persona súper comprensiva, súper dialogante. Es un poco controlador pero que tiene muchas maneras de hacer que chocan con el padre típico y eso para mí ha sido un referente, no únicamente en el tema de la masculinidad, sino a nivel pedagógico me parece muy sano. Es una persona que te pregunta cómo estas, como te sientes. Es muy resolutivo. Es muy empático. Luego cuando mi madre murió, tuvo él que asumir esas tareas y todos esos cuidados. Eso me ha hecho ser más cuidadoso. (E4, trabajador social, 26 años)
\end{abstract}

Finalmente, el tercer modelo familiar serían familias donde existe una ausencia de referentes masculinos. Este sistema familiar se caracteriza principalmente por la ausencia del padre, ya sea debido a las exigencias del trabajo o su poca disposición para implicarse en lo doméstico, en la crianza y no compartir un espacio de afectividad con sus hijas/os. Un efecto directo de esta ausencia los participantes lo atribuyen a un impacto negativo en su desarrollo causando carencias emocionales: "Mi madre era la cuidadora. Tengo pocos recuerdos de haber compartido con mi padre. No había una presencia masculina en casa" (E3, empresario, 34 años).

\subsection{Pubertad: Virilidad y cuestionamiento de la heterosexualidad}


Nos pareció relevante indagar la etapa transicional de la pubertad y la adolescencia ya que este periodo da luces del modo en que instala el modelo hegemónico en la identidad de los varones. En particular, nos llama la atención el papel de la sexualidad como vehículo socializante de los mandatos de género y las prácticas sexo-genéricas que marcarán la vida posterior de los participantes. En general, hallamos que esta etapa está marcada por la heteronormativización de las relaciones sexo-genéricas. Con esto, nos referimos a la instalación de la norma de género a nivel subjetivo y junto con ello, la paradoja producida por las diversas experiencias homoeróticas y exploraciones sexuales con otros pares durante la adolescencia y la pubertad:

Viví un cambio bien compartido con mis amigos del barrio, eran cambios que vivimos en complicidad. Me acuerdo que una vez hicimos un club en una plaza y una vez estábamos masturbándonos al mismo tiempo todos entonces fue como algo pícaro, la picardía de explorar y compartir eso que estábamos viviendo. Fue la manera en que lo fuimos asimilando. La verdad nunca me sentí incómodo y nunca me hice esas preguntas en ese momento. To miraba a mi y al resto sin "ojos morales". (E1, Sociólogo, 27 años)

Junto con ello, en esta etapa la virilidad se impone como modelo. También refieren por primera vez a notar que existen diferencias entre niños y niñas, y que las relaciones entre iguales comienzan a gestarse a partir de la competencia y el logro, por ejemplo, en espacios deportivos y de ocio.

"En la adolescencia intentas hacerte el machote, el hombre. Por ejemplo, con la bebida, si aguantabas mucho bebiendo, se decía que eras más hombre. Con el deporte también, se competía por quien era más hábil, más fuerte. Subía el pecho (risas) aparentaba que era más fuerte. Yo creo que eso me debía dar seguridad para reafirmarme en eso. Mi actitud corporal cambiaba e incluso hablaba más grave" (E 17, psicólogo, 27 años).

\subsection{Hombres: Afecto entre pares y personas LGBTI como referentes}

En muchos relatos, los participantes señalan haber interactuado con personas LGBTI y a través de estas, haber transformado y modificado ideas negativas y prejuicios acerca de estos colectivos. Esto les hizo personas más tolerantes a la diferencia, respetuosos de la diversidad sexual y con mayor sensibilidad ante la violencia homo/lesbo/transfóbica, poniendo en jaque mandatos centrales de la masculinidad hegemónica heteronormativa (14 de 19 se declaran heterosexuales): "Conocí a mucha gente bisexual, tengo varias amigas lesbianas y eso te abre un abanico de posibilidades que se agradece" (E4, trabajador social, 26 años); "Este amigo gay también fue significativo porque en mi pueblo no conocía a nadie homosexual y me abrió a la mente a otras posibilidades” (E3, empresario, 34 años).

Tal como vimos, la castración emocional sería una de las consecuencias de la masculinidad hegemónica. En general, los participantes refieren que la forma en que se relacionan con sus pares tiene una importante tendencia al contacto corporal y a la expresión afectiva como una manera de contravenir los dictámenes homofóbicos y violentos de las interacciones masculinas machistas. Es decir, son hombres que abiertamente buscan el contacto afectivo y le dan valor a su emocionalidad y muestran abierta incomodidad en espacios de hegemonía masculina donde por ejemplo se reproducen bromas y comentarios machistas.

\subsection{Mujeres}

\subsubsection{Sensibilización a través del feminismo}


Los participantes refieren que desde muy jóvenes ha habido una preferencia en la socialización con mujeres. Dicen sentirse más cómodos relacionándose con ellas porque les permite cultivar espacios de mayor intimidad y con menos juicios: "Pienso que he aprendido más de mujeres que de hombres" (E6, economista, 42 años); "Siempre me he sentido mejor hablando con mujeres, más escuchado y sentía que podía expresarme como yo era" (E3, empresario, 34 años).

\subsubsection{Conciencia de privilegio}

En los relatos de varios de los participantes podemos encontrar que su acercamiento al feminismo fue gracias a otras mujeres (amigas, compañeras de partido, colegas, parejas). Es decir, una vez que estos hombres conocieron las ideas y valores del feminismo, se produjo un quiebre en ellos, en su identidad y en la concepción que tenían sobre las relaciones sexo-genéricas. El haberse acercado a lecturas feministas, manifestaciones y colectivos políticos produjo varias transformaciones en ellos y en su identidad masculina, haciéndose consciente de sus privilegios: "Tuve mucha conciencia del feminismo por ella. Por lo intelectual, era muy lista. Fue curioso porque fue una deconstrucción después que lo dejamos. Me empecé a revisar por dentro. Volví a una masculinidad que siempre había renegado y no me había dado cuenta. Son las mujeres las que me han hecho cambiar mi masculinidad, las que me han marcado más son las mujeres. La conciencia ha sido tardía" (E7, psicólogo, 31 años).

\subsection{Identidad}

Esta dimensión resulta fue central para analizar los relatos. Ante la pregunta reflexiva ¿Qué tipo de hombre crees que eres? Los participantes dieron luces de características tanto de rasgos de personalidad como de atributos personales. En primer lugar, se consideran hombres sensibles. Curiosamente, esta categoría fue una de las más altas en saturación conceptual, ya que se repite esta idea en la mayoría de las respuestas de los entrevistados. Prácticamente todos estos hombres se perciben a sí mismos como hombres que poseen una profunda conexión con sus emociones y que todo lo vinculado a lo emocional tiene un valor significativo en sus vidas: "Yo creo que soy un hombre sensible. Me gusta mucho escuchar. Soy blando, físico y emocionalmente. Muchas películas me hacen llorar. Estoy gordo. Me gusta, no me molesta" (E8, antropólogo, 27 años); "Soy sensible, de hecho, me emociono bastante cuando veo situaciones de solidaridad" (E12, integrador social, 42 años).

Sin embargo, quienes más se desmarcaron de identificarse como hombres en tanto condición fueron quienes se identifican como hombres trans, ya que el proceso de identidad para ellos se ha dado de un modo diferente (dos participantes se identificaron como hombre trans y uno como no binario):

Creo que sentirse hombre para una persona trans es algo muy fuerte. Al principio tenía
contradicciones con esto de pasar de ser mujer a hombre, pero en la medida que fui
conociendo otros hombres distintos, quizás con los que me pudiera identificar, me
empezó a pasar que esto de ser hombre fue perdiendo su carga negativa (...) Quiero
ser un hombre a futuro. Esto se está construyendo hace algo relativamente poco. Es
decir, una vez que empiece el tratamiento, quiero poder explorar diferentes expresiones
de género. Yo creo que soy una persona bastante femenina. Me ha costado entender
que eso no es lo mismo que ser chica. (E11, estudiante, 23 años)

4.5.1. Oposición a la violencia y cuidado 
Los participantes se declaran abiertamente en contra de la violencia de género y de cualquier forma de violencia. En general, se identifican como personas de paz y que creen en el diálogo y en construir caminos de comunicación no violentas con los demás: "Yo siempre he tenido una sensibilidad extrema por los derechos humanos, por la gente sin vivienda, ya sea los migrantes. Siempre me han preocupado las personas e ir contra la prepotencia, contra el abuso de poder" (E12, integrador social, 42 años); "A mí la violencia de género me afecta, me da asco" (E4, trabajador social, 26 años); "Cuando algo no lo he hecho bien, siento dolor. Creo que me importa el cuidado y me preocupo por los demás. Estoy en eso ya que me motivó el rechazo a la violencia y la filosofía feminista" (E9, trabajador automotriz, 56 años).

\subsubsection{Valores igualitarios}

Si bien existe una gran variedad de valores que son parte del repertorio moral de estos hombres brotan de forma transversal en todas las respuestas dos valores igualitarios por excelencia: la equidad y la igualdad. Los participantes lo refieren como los valores del feminismo. Tienen un claro acercamiento inicial a estas ideologías a través de partidos políticos vinculados al socialismo democrático, colectivos de izquierda y movimientos ciudadanos y comunitarios como el 15M en España "Me inspira el amor y el feminismo como potencial revolucionario" (E19, cientista político, 25 años); "Conocí y leí de feminismo. Creo que hay una dimensión más personal que tiene la política. Para mí es la deuda histórica que tiene la izquierda" (E1, Sociólogo, 27 años).

\subsection{Educación}

Si bien, parte de los objetivos de nuestra investigación era poder constatar qué tipo de valores igualitarios educan estos varones y si lo están haciendo de forma efectiva, nos interesaba saber a través de qué medios ellos promueven activamente estos valores. En este caso, los participantes afirman que existen tres principales maneras de poder transmitir y educar estos valores: la primera sería siendo un referente de género para otros hombres, ya que consideran que, para educar a otros hombres en temas de género, masculinidades y prevenir la violencia machista es importante primero hacerlo a través del ejemplo. Esto quiere decir que estos valores e ideas necesitan ser transmitidos en el día a día: "Yo creo que se tiene que provocar en el entorno, por ejemplo, yo lo hago con mis amistades. Yo creo que es importante enseñar y hablar a través de conversaciones. Hablar sobre sexo, sobre todo que los hombres podamos hablar explícitamente como nos relacionamos sexualmente con mujeres. Creo que eso se hace poco" (E5, musicoterapeuta, 34 años).

La segunda es la confrontación desde el privilegio a través de la renuncia en espacios de poder transformando ideas y hablando de igual a igual a través de conversaciones que contribuyan a que otros hombres se hagan conscientes de sus comportamientos machistas, pudiendo reflexionar sobre la manera que están dando uso a su privilegio, algo que para muchos es ignorado completamente: "Algo que me siento muy orgulloso de mi grupo de amigos, fue que hace poco, como un año, una chica de Tenerife pasó un nude, se equivocó y lo mandó y le llegó a un amigo mío y él compartió la foto de esta chica en tres grupos de Whatsapp. Yo estaba en los tres. Y me sentí super orgulloso porque varios le dijeron, ¿Qué coño estás haciendo? Te pasaste, para qué pasas esto. Y él se sintió tan mal al ver que la cagó que incluso, habló con la chica, y le pidió disculpas. Le dijo que había pasado la foto y tal. Todos le paramos los pies" (E13, psicólogo, 24 años). 
To pienso que los tíos sobre todo y me incluyo, no somos conscientes de lo que quiere decir dominación y privilegios, ya que el ejercicio de reconocer nuestros privilegios es algo que nadie nos enseña a hacer y cuando nos confrontan con ellos, nosotros no los identificamos como tal porque ha sido toda nuestra vida eso. Es renunciar a tu vida. Nos cuesta renunciar a nuestra vida. Entonces yo a veces pienso en qué privilegios tengo yo para saber desde donde me tengo que deconstruir. $Y$ ahora claro, hablamos de cursos de paternidades, yo digo qué cosas no le quiero enseñar como hombre a mi hijo, pero primero tengo que saber qué es lo que hago mal. Esperas la solución desde afuera, como los hombres. Esperas un listado de afuera que te digan qué hacer. Hasta la forma racional de pensar es patriarcal. (E6, economista, 42 años)

Por último, promover espacios colectivos entre hombres y que faciliten la deconstrucción del género. Este mecanismo comprendería, por una parte, un proceso personal de revisión de la identidad masculina propia y de las prácticas machistas que cada uno identifica, y, por otra parte, abrirse a compartir estos miedos, dudas e incertidumbres en colectivo: "Si yo te explico mi experiencia puede ser que tú decidas probarla. Si esto me lo hubiese explicado un hombre, creo que hubiese tenido un efecto mucho más rápido que una mujer. La experiencia vivencial es muy importante. Un manual no te lo va a hacer" (E7, psicólogo, 31 años); "Tiene que ser tú a tú. Para mí es un proceso que se da colectivamente" (E6, economista, 42 años).

\title{
4.7. Cambios
}

En este apartado intentamos dar cuenta de las consecuencias que ha tenido en la vida de estos hombres haber decidido posicionarse desde una vereda distinta a la masculinidad hegemónica. Los participantes declaran en primer lugar, que la calidad de sus relaciones interpersonales ha mejorado considerablemente: ellos connotan positivamente que pasan más tiempo con sus familias, disfrutan de la paternidad y la intimidad que se ha construido con sus amistades, poseen redes de apoyo sólidas y tiempo de calidad con seres queridos:

\begin{abstract}
Esto me ha hecho entender la relación con mi padre y tener una perspectiva de género feminista y al tener una confrontación con otro hombre, poder ser más asertivo y dialogar con otro hombre, intentar cambiarlo desde la asertividad. (E12, integrador social, 42 años)

Me siento fenomenal y en mi casa se vive fenomenal. Mi mujer, por ejemplo, ella lo explica. Dice que su marido participa de un grupo de hombres y participa de esas cosas. Con mis hijas también lo veo e invierto mucho tiempo con mi familia. Tengo un nieto y ahora voy por otro. Esto para mí tiene un valor. Si no hubiese tenido esta relación con personas del movimiento feminista e igualitario, seguro que no me hubiese preocupado tanto de los hijos o de los nietos. Donde más noto cambios en mi vida es con mi relación con los demás. (E9, trabajador automotriz, 56 años)
\end{abstract}

Junto con ello, nuestros participantes refieren tener una perspectiva distinta del amor y las relaciones sexo-afectivas. Se dan cuenta que el rol masculino tradicional se transformaba en un peso para ellos y actualmente se sienten más aliviados y con menos presión. Se ha producido una brecha porque ya no están centrados en el rendimiento sexual y en el placer auto centrado. Se han percatado que esto les ha abierto puertas nuevas a otras formas de placer en relación: "Me afecta en mi propia capacidad de poder disfrutar de mi propia pareja, de mi propia sexualidad y aceptarme desde ahî" (E2, Psicólogo, 32 años). Finalmente, algunos de nuestros participantes refieren sentir un cambio a nivel interno, lo cual ha modificado la relación que tienen consigo mismos. Esto ha repercutido en sus hábitos alimenticios, su salud y autocuidado y también la forma en cómo se comunican, expresar sus emociones y necesidades: "Lo primero es estar más a gusto conmigo mismo, de asumir mis propias limitaciones y asumir las rayadas" (E19, cientista político, 25 años); “Tengo más autoconciencia de mi salud y mi estado físico. Creo que es 
importante tener hábitos" (E9, trabajador automotriz, 56 años). Incluso algunos de ellos viven esto con un sentido de trascendencia y algo que dota de valor a sus proyectos de vida:

$A$ veces no me reconozco. Siento que soy otra persona. Mis emociones son diversas, muy guays, me encantan. Disfruto mis emociones incluso con niños pequeños, ahora sé cómo interactuar con ellos. Conmigo mismo. Con mis cuidados hacia mí, mi alimentación. Siempre me encanta cocinar y cocinar para los demás. Estoy más a gusto conmigo mismo. Creo que desde la mirada ecofeminista, incluso para mí la relación con la tierra ha cambiado. Es una perspectiva global para mí. Soy otra persona. Ya no me imagino de otra forma. Creo que es irreversible. (E16, trabajador social, 34 años)

\section{Conclusiones}

De modo general, podemos señalar que los hitos, experiencias de vida y motivaciones que han hecho que estos hombres construyan una identidad masculina alternativa han sido sumamente variados: hay quienes señalan que se sensibilizaron a través de lecturas feministas, otros al cursar una asignatura optativa de género en la universidad, otros gracias a sus parejas, quienes los inmiscuyeron en el feminismo y otros debido a su propia experiencia familiar con modelos de hombres que rompían el esquema tradicional. Todas estas experiencias de quiebre o ruptura, van erigiendo en ellos una serie de cambios y comportamientos. Es decir, no contamos con los elementos suficientes para aseverar con certeza que un único motivo fue el detonante de este cambio identitario. Hemos de destacar que estos hitos y experiencias de ruptura se presentaron en diferentes momentos de su vida: algunos se dieron siendo ya mayores y otros más de joven al ver que su masculinidad durante la adolescencia no encajaba con el modelo de la masculinidad hegemónica y otros influenciados por sus parejas, por ejemplo.

Respecto a las familias, vemos la importancia que ha tenido para algunos tener un padre que sea un referente de género igualitario. De hecho, varios de nuestros participantes hacen hincapié en la falta de modelos de referencia de hombres no machistas o igualitarios. Resulta clave también la presencia de hombres gays, trans y personas de la diversidad sexual como modelos de referencia masculinos que rompen con el estereotipo.

Otro punto relevante es la conciencia sobre el privilegio que viene dado por los espacios de varones. Tal como vimos, muchos hombres igualitarios muestran rechazo y distancia a compartir espacios con hombres machistas, ya sea en lugares de ocio, políticos o deportivos. Esto nos hace reflexionar sobre el rol que tienen estos varones como agentes de cambio en sus comunidades y que, si bien tienen el legítimo derecho de auto marginarse, es aún más difícil propiciar puntos de quiebre y confrontación con otros pares que aún no están sensibilizados ni les interesa implicarse en estas temáticas. En relación al tránsito de la pubertad y la adolescencia, pensamos que lo dicho por los participantes es muy relevante en la medida que da luces para poder intervenir desde el ámbito de lo educativo, en lo curricular y extracurricular, así como futuras líneas de educación en género e investigación.

Sobre los valores, resulta llamativo lo unánime de las respuestas y los relatos: implicarse en la erradicación de la violencia de género es un gesto de justicia social, de humanidad y de empatía. Ni siquiera pasa solamente por algo ideológico o político. Es un acto de compromiso moral. Es decir, los valores de la igualdad y la equidad se presentan como un 
piso mínimo de sana convivencia social entre varones y mujeres y vendrían a ser el asfalto de un camino que se encuentra en proceso de construcción.

\section{Referencias}

Azpiazu, J. (2017). Masculinidades y feminismo. Virus editorial.

Badinter E. (1992). La identidad masculina. Alianza Editorial.

Bardi, L., González, E., Leyton, C. y Martínez, V. (2005). Identidad sexual: Proceso de definición en la adolescencia. Revista Docencia, 26, 43-51.

Bolívar, A. (2002). ¿De nobis ipsis silemus? Epistemología de la investigación biográfico-narrativa en educación. Revista Electrónica de Investigación Educativa, 4(1), 1-24.

Bonino, L. (2008). Hombres y violencia de género. Más allá de los maltratadores y de los factores de riesgo. Ministerio de Igualdad

Bourdieu, P. (1998). La dominación masculina. Editorial Anagrama.

Connell, R. W. (1995). The social organization of masculinity. Universidad de California Press

Covacevich, C. y Quintela-Dávila, G. (2014). Desigualdad de género, el currículo oculto en los textos escolares chilenos. División de Educación. BID.

Espada Calpe, J. M. (2004). Poder, masculinidad y virilidad.

http://www.berdingune.euskadi.eus/contenidos/informacion/material/eu_gizonduz/adju ntos/podermasculinidadyvirilidad.pdf

Del Río, F. (2019). Variables no académicas que explican la brecha de género en matemática: Datos de Chile. Universidad Diego Portales.

Gabarró, D. (2008). Transformar la masculinidad machista: Un reto social. BID

Gil Calvo, E. (2001). Nacidos para cambiar: cómo construimos nuestras biografías. Taurus.

González Moreno, M. C. y Camacaro Gómez, D. (2013). Desandando las rutas de la masculinidad. Comunidad y Salud, 11(1), 68-78.

Guasch, O. (2006). Héroes, científicos, homosexuales y gays. Bellaterra.

Idescat. (2013). Instituto de estadística de Cataluña. IDESCAT.

Izquierdo, M. J. (2007). Lo que cuesta ser hombre: costes y beneficios de la masculinidad, Comunidad y Salud, $11(1), 1-27$.

Kaufman, M. (1994). Men, feminism, and men's contradictory experiences of power. Theorizing Masculinities. Sage Publications.

Kimmel, M. (1994). Homofobia, temor, vergüenza y silencio en la identidad masculina en fear, shame and silence in the construction of gender identity. Sage Publications.

Llorente, M. (2009). Los nuevos hombres nuevos. Ediciones Destino.

Montesinos, R. (2002). Las rutas de la masculinidad. Gedisa Editores.

Nadal, K (2008). Preventing racial, ethnic, gender, sexual minority, disability, and religious microaggressions: Recommendations for promoting positive mental health. Theory, Research, Practice and Training, 2(1), 22-27.

Olarte Ramos, C. A. y de Keijzer Fokker, B. (2018). Se solicitan hombres: La experiencia masculina en talleres sobre afectividad. Quaderns de Psicología, 20(1), 7-22. 
Organización Mundial de la Salud (2014). Prevención del suicidio: Un imperativo global. OMS.

Promundo y ONU Mujeres. (2017). Understanding masculinities: Results from the international men and gender equality survey. ONU.

Rubin, G. (1975). El tráfico de mujeres: Notas sobre la "economía política” del sexo. Nueva Antropología, 30(8), 96-145.

\section{Breve CV del autor}

\section{Pedro Uribe Roncallo}

Psicólogo por la Universidad Alberto Hurtado, Máster en educación en valores y ciudadanía, Universidad de Barcelona. Especialista en Género, Masculinidades y Sexualidad. Técnico en prevención de violencias de género. Actualmente se desempeña como terapeuta en la consulta privada y también es director ejecutivo en Ilusión Viril, fundación dedicada a la prevención de la violencia de género y a la promoción de masculinidades igualitarias, proyecto creado por él en 2018 desde Santiago de Chile, desde el cual genera contenido educativo con enfoque de género y masculinidades en redes sociales para toda Latinoamérica y España. ORCID ID: https://orcid.org/0000-00024095-9035. Email: pedromigueluribe@gmail.com 